\title{
Remeshing procedure for discrete membrane finite element: application to woven composite forming
}

\author{
Abel Cherouat $^{\mathrm{a} *}$, Laurence Moreau $^{\mathrm{a}},{\text { Rezak } \text { Ayad }^{\mathrm{b}} \text { and Tarak Ben Zineb }}^{\mathrm{c}}$ \\ ${ }^{a}$ Charles Delaunay Institute, Equipe Gamma3, University of Technology of Troyes, 12 rue Marie Curie, \\ BP2060, 10010 Troyes, Cedex, France; ${ }^{b}$ Laboratoire d'Ingénierie et de Sciences des Matériaux/LISM, \\ Université de Reims Champagne-Ardenne, UFR SEN, Moulin de la Housse, BP 1039, 51687 Reims, \\ Cedex 2, France; ${ }^{\circ}$ Université de Lorraine/LEMTA, 2 rue Jean Lamour, 54500 Vandoeuvre-les-Nancy,
}

France

\begin{abstract}
Pre-impregnated woven fabric is an increasingly important component as the reinforcement phase of composite materials for many mechanical structures (automotive and aerospace). Modelling woven fabrics is difficult due, in particular, to the need to simulate the response both at the scale of the entire fabric and at the meso-level, the scale of the fibre that composes the weave. Here, we present new finite element for the simulation of the 3D, preimpregnated woven fabric preform. Continuum-level modelling technique that, through the use of an appropriate bi-component unit cell (fiber rotation quadrilateral element connected to truss elements), captures the deformation of the mesostructure of the fabric without explicitly modelling every fibre. Simulations of the experiments demonstrate that the finite elements are capable of efficiently simulating large, complex structures and forming processes.
\end{abstract}

Les tissus pré-imprégnés est une composante importante dans le renforcement de matériaux composites pour de nombreuses structures mécaniques (automobile, aéronautique). Le désir d'explorer de nouvelles applications de ces matériaux compétitives, il est nécessaire de mettre au point de modèle de calcul efficace pour la modélisation de la déformation des tissus pré-imprégnés. Dans cette étude, nous présentons un nouvel élément fini bi-composant (élément FRQ + éléments de barres) pour la simulation 3D des tissus à l'échelle de la méso-structure du tissu, sans modélisation explicite chaque fibre. Des essais expérimentaux sont réalisés pour valider notre approche.

Keywords: pre-impregnated fabric; FEM; adaptive remeshing; composite forming; FRQ element; truss element

Mots-clés: tissus pré-imprégnés; FEM; remaillage; mise en forme; elément FRQ; eléments barre

\section{Introduction}

The simulation of the manufacturing of a woven fabric reinforced composite part with a liquid composite moulding-like process, which involves draping or drawing of the preform and impregnation of the preform, includes several stages. First, a mould is designed with CAD software, and then a numerical tool is used to compute the deformations of the woven

*Corresponding author. Email: abel.cherouat@utt.fr 
fabric inside the mould. The choice of manufacturing process depends on the type of not polymerised matrix (or resin) and fibres, the temperature required to form the part and the cost-effectiveness of the process. The numerical simulation of composite forming is an efficient means of evaluating factors related to manufacturing processes and an efficient help to design pre-forming sequence for the manufacturing of fabric reinforced composites. It is possible to detect the main problem occurring during the shaping deformation and to obtain good quantitative information on the forming process (Hou, Ye, \& Mai, 1997; Rudd \& Long, 1999; Trochu, Ruiz, Achim, \& Soukane, 2006).

Modelling pre-impregnated woven fabrics is challenging due in part to the complexity of the weave architecture. At the mesoscale, a woven fabric consists of two orthogonal sets of fibres (warp and weft) interlaced with one another. The resulting undulation of each yarn over and under the orthogonal fibres is described as crimp, and wherever the fibres cross is termed a cross-over point. The crimp amplitude is the wave amplitude of the fibre. The macroscopic response of the fabric is highly dependent on the current orientation and crimp of the fibres.

Different levels of modelling intervene in the simulation of woven reinforcement forming: (1) architecture design level, (2) preliminary design level, (3) mechanical level by computational software and (4) optimisation level (Lim, Ramakrishna, \& Shang, 1999; Lomov et al., 2007). Most of these levels are integrated and take into account specific constraints of manufacturing processes. The particular form of composite fabrication (pre-preg) begins with the pre-impregnation of reinforcement materials with a resin. The combining of these two materials occurs prior to the moulding process and therefore enables a very accurate reinforcement to resin ratio to be achieved. Pre-preg materials are used extensively in the aerospace or automotive industry due to their ability to maximise strength to weight ratios. Pre-pregs are pliable and therefore able to be cut into various shapes or patterns prior to processing into the moulded products. But for the manufacturing of non-developable composite part (part that cannot make flat un-stretched), a new problem intervenes in the design chain resulting from the number of parameters influencing the global behaviour of composite forming process. The ability to define, in advance, the ply shapes and material orientation allowed the engineers to optimise the composite structural properties of the composite products for maximum strength, maximum material utilisation and maximum lay-up efficiency (Boisse, Buet, Gasser, \& Launay, 2001; Cherouat \& Billoët, 2001; Cherouat, Gelin, Boisse, \& Sabhi, 1995; ElHami, Radi, \& Cherouat, 2009; Liu, Chen, Li, \& Sherwood, 2005; Potluri, Parlak, Ramgulam, \& Sagar, 2006; Rozant, Bourban, \& Manson, 2000).

The composite manufacturing process involves large displacements and rotations and large shear of weft and warp fibres, which can have a significant effect on the processing and structural properties of the finished product. The formulation of new and more efficient numerical models for the simulation of the shaping composite processes must allow for reduction in the delay in manufacturing of complex parts and an optimisation of costs in an integrated design approach (Boisse, Gasser, Hagege, \& Billoet, 2005; Cherouat, Borouchaki, \& Billoët, 2005; Lim \& Ramakrishna, 2002; Parsons, Weerasooriya, Sarva, \& Socrate, 2010; Pickett, Creech, \& de Luca, 2005; Warby, Whiteman, Jiang, Warwick, \& Wright, 2003). Several modelling approaches have been developed to account for the evolution of the orthotropic directions during high shearing, and these approaches include the geometrical and the finite element approaches. The geometrical approach so called fishnet algorithms is used to determine the deformed shape of draped fabrics. This method, where the fabric is placed progressively from an initial line, provides a close enough resemblance to handmade draping (Borouchaki \& Cherouat, 2003; Cherouat et al., 2005; Long \& Rudd, 1994; Mark \& Taylor 1956; Van Der Ween, 1991). They are very fast and fairly efficient in many pre-preg draping cases. Nevertheless, this method has major drawbacks. They account neither for the mechanical behaviour of 
the fabric nor for the static boundary conditions. This last point is very important in the case of forming with punch and die (such as in the pre-forming of the resin transfer molding (RTM) process). The loads on the tools, especially on the blank holder, influence the quality of the shaping operation, and therefore, need to be considered in simulations (Hancock \& Potter, 2005; Harrison, Clifford, Long, \& Rudd, 2004; Potluri, Sharma, \& Ramgulam, 2001; Vanclooster, Lomov, \& Verpoest, 2009).

The alternative to the geometrical approach consists of a mechanical analysis of the fabric deformation under the boundary conditions prescribed by the forming process. This requires a specific model of the woven reinforcement and its mechanical behaviour. The mechanical behaviour of woven fabrics is complex due to the intricate interactions of the fibres. It is a multi-scale problem. The macroscopic behaviour is very much dependent on the interactions of fibres at the meso-scale (scale of the woven unit cell) and at the micro-scale (level of the fibres constituting yarns). Despite the great amount of work in the field, there is no widely accepted model that accurately describes all the main aspects of fabric mechanical behaviour. The main model families come from the multi-scale nature of the textile.

A first family of models is obtained by homogenising the mechanical behaviour of the underlying meso-structure and considering the fabric as an anisotropic continuum (Boisse et al., 2001; Cherouat et al., 1995; Parsons et al., 2010; Potluri et al., 2006). If these models can easily be integrated in standard finite element using conventional shell or membrane elements, then the identification of homogenised material parameters is difficult, especially because these parameters change when the fabric is strained and when, consequently, the directions and the geometry (crimp, transverse sections, etc.) of the fibres change. Some of these approaches will be described, especially a non-orthogonal constitutive model (Hagège, Boisse, \& Billoët, 2005; Peng \& Cao, 2005; Spencer, 2000; Ten Thije, Akkerman, \& Huetink, 2007; Xue, Peng, \& Cao, 2003; Yu, Pourboghrat, Chung, Zamploni, \& Kang, 2002) and an anisotropic hypoelastic continuous behaviour for fibrous material based on an objective derivative using the rotation of the fibre (Hagège et al., 2005; Ten Thije et al., 2007). Conversely, some authors present fully discrete models of fabrics (Duhovic \& Bhattacharyya, 2006; Sharma \& Sutcliffe, 2004). Each yarn or each fibre is modelled and is assumed to be a straight or a curved beam or truss. Sometimes they are modelled as 3D domains (Sharma \& Sutcliffe, 2004). Springs are often used to model warp and weft yarn interactions. In the objective of fabric forming simulations, some authors extend the discrete modelling to the whole textile structure that is represented by a network of interwoven trusses or beams with different tensional and rotational springs. Accounting for the simplicity of each component, the whole textile structure deformation can be computed.

Nevertheless, the computational effort needed is relatively significant. At present, this method is restricted to simple geometry of the local yarn and relatively simple mechanical behaviour. When a fine model of the fibrous yarns is used, the analysis can only consider a small part of the textile reinforcement such as a few woven or knitted cells. The semi-discrete approach is a compromise between the above continuous and discrete approaches (Parsons et al., 2010; Spencer, 2000; Yu et al., 2002). A finite element method is associated to a mesoscopic analysis of the woven unit cell. Specific finite elements are defined that are made of a discrete number of woven unit cells. The mechanical behaviour of these woven cells is obtained by experimental analyses or from 3D finite element (FE) computations of the woven cell. The nodal interior loads are deduced from this local behaviour and the corresponding strain energy in the element deformation. In this study, the finite element semi-discrete approaches are used to simulate the deformation of composite fabrics by shaping process. These approaches, while giving good results and being efficient in terms of computing time, are generally somewhat complex and sometimes very challenging to implement into commercially available FEA packages. 
The mechanical approach is based on a meso-structural description for finite deformations and geometrical non-linearity. The not polymerised resin has a viscous behaviour and the reinforced fibers are treated as unidirectional non-linear elastic behaviour. The unit cell of the mesoscopic model used here for a plain-weave fabric consists of bi-component finite elements. The tensile load is carried by the $1 \mathrm{D}$ element that will capture the changes in the orthotropic directions during the shearing. The $2 \mathrm{D}$ element accounts only for the shearing resistance of the fabric and hence, has no tensile stiffness. The bi-component finite elements for modeling composite fabric behaviour are based on 3D membrane finite elements representative of resin behaviour and truss finite elements representative of warp and weft fibers behaviour. New linear fibre quadrilateral rotational finite element FRQ4 is developed to characterise the resin behaviour and implemented into the standard finite element code Abaqus/Implicit with the user element subroutine. The concept of fibre plane rotation, proposed by (Ayad, 1993), is described through the four nodes element. The efficiency of the proposed model resides in the simplicity of its finite element discretisation and the performance of its mechanical background (Borouchaki, Cherouat, \& Billoët, 1999; Fan, Tang, Tsui, Chan, \& Lee, 2006; Long, 2001; Umer, Bickerton, \& Fernyhough, 2008; Vilnis Frishfelds, Staffan Lundström, \& Jakovics, 2008).

Due to large displacement due to forming process, the bi-component finite element mesh representing the workpiece undergoes severe shear of fibres hence, necessitates remeshing or the generation of a new mesh for the deformed/evolved geometric representation of the computational domain (Borouchaki, Cherouat, Laug, \& Saanouni, 2002; Cherouat, Borouchaki, \& Giraud-Moreau, 2010; Cho \& Yang, 2002; Giraud-Moreau, Borouchaki, \& Cherouat, 2005). It is therefore necessary to update the mesh in such a way that it conforms to the new deformed geometry and becomes dense enough in the critical region while remaining reasonably coarse in the rest of the domain. In this paper, we give the necessary steps to remeshing a mechanical composite structure subjected to large displacement. An important part is constituted by geometric and physical error estimates. A 3D finite element analysis has been performed using the explicit finite element formulation.

\section{Mechanical behaviour of pre-impregnated fabric}

The mechanical behaviour of composite fabrics is complex and it is a multi-scale problem due to the interactions of the fibres or yarns. The macroscopic behaviour is very much dependent on the interactions of fibres at the meso-scale (scale of the woven unit cell) and at the micro-scale (level of the fibres constituting yarns). Despite the great amount of work in the field, there is no widely accepted model that accurately describes all the main aspects of fabric mechanical behaviour. The main model families come from the multi-scale nature of the textile. During the forming process of woven fabric, the two main modes of deformation at the mesoscopic scale are the stretching of the fibres due to fibres undulation and the in-plane shearing of the fabric resulting in a change of the angle between the warp and the left yarns. In the deep-drawing or the draping of woven fabrics, the in-plane shear of fibres is the principal mode of deformation and is very different than the sheet metal (Bergsma \& Huisman, 1988; Padmanabhan, 2008). Two straight lines drawn alternatively on warp and weft fibre directions during the forming deformation become curved but remain continuous (see Figure 1). The absence of inter-yarn sliding ensured by the fabric weaving, viscoelastic behaviour of resin and friction fibre/fibre and fibre/resin) can be observed over the main areas of the fabric (i.e. far enough from the free edges of the fabric). Also, for the composite fabrics based on high modulus, the compressive as well as bending stiffness are negligible compared to the in-plane membrane stiffness. The assumption is that each cross-connection of straight 


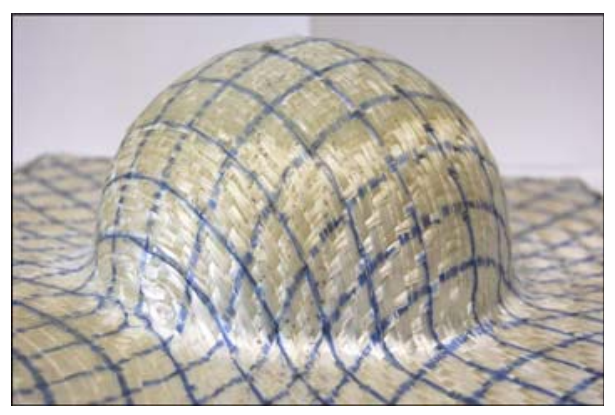

Figure 1. Woven fabric deformation mode.

warp and weft fibre before deformation remains cross-connected during the deformation. The basic assumptions for the mechanical forming are that the woven fabric is considered as a continuous 3D material. The warp and weft fibres are represented by a truss in which connecting points are hinged and the membrane resin is coupled kinematically to the fabric at these connecting points.

In the unit cell of the mesoscopic model used here for a plain-weave fabric each fibre and resin is modelled and is assumed to be a straight or a curved beam or truss. The tensile load is carried by the $3 \mathrm{D}$ truss or beam elements that will capture the changes in the orthotropic directions during the shearing. The $3 \mathrm{D}$ membrane or shell element accounts only for the shearing resistance of the fabric and hence, has no tensile stiffness. The interaction between warp-weft yarn and resin-fibres is negligible. In this approach, the stress and strain of a continuous unit cell material are related to fibrous reinforcement using the constitutive relation in a nonorthogonal frame directed by the fibre directions (Cherouat \& Borouchaki, 2009; Dafalias, 1983; Gilormini \& Roudier, 1993; Gommers, Verpoest, \& Van Houtte, 1996; Luo \& Verpoest, 2002; Peng \& Cao, 2002; Ten Thije et al., 2007). The deformed geometry of the unit cell in three dimensions is fully determined by the macroscopic deformation gradient. At the continuum level, at each material point in the undeformed configuration, the fabric is described by unit vectors aligned with the warp and weft fibres. These fibre vectors are material lines, and the deformation gradient specifies their orientation and length everywhere on the deformed fabric.

In this analysis, $x$ denotes position in a fixed, Eulerian, orthogonal frame of reference and $X$ denotes position in an embedded material, orthogonal frame following the material deformation. The unit vectors define the local orthogonal reference frame that rotates with the continuum material and the material basis vectors form a non-orthogonal frame that follows the fibre direction. In this case, for each connecting point $\vec{X}^{\mathrm{f}}$ of warp and weft yarns is associated a material position space of a resin $\vec{X}^{\mathrm{m}}$. At the connecting points, we have $\vec{X}^{\mathrm{f}}=\vec{X}^{\mathrm{m}}=\vec{X}$ before deformation. The current position of these points is obtained by:

$$
\left\{\begin{array}{c}
F^{\mathrm{f}}\left(\vec{X}^{\mathrm{f}}, t\right)=\frac{d \vec{x}^{\mathrm{f}}}{d \vec{X}^{\mathrm{f}}} \quad \text { fibres } \\
F^{\mathrm{m}}\left(\vec{X}^{\mathrm{f}}, t\right)=\frac{d \vec{x}^{\mathrm{m}}}{d \vec{X}^{\mathrm{m}}} \quad \text { resin }
\end{array}\right.
$$

where $F^{\mathrm{f}}$ and $F^{\mathrm{m}}$ are the deformation gradient tensor of fibre and resin, respectively. The relationship of the no sliding inter-fibre can write at each connecting point as $\vec{x}=\vec{x}(\vec{X}, t) / \vec{x}^{\mathrm{f}}=\vec{x}^{\mathrm{m}}=\vec{x}$. The gradient of transformation of the pre-impregnated woven fabric $\mathbf{F}$ and the pseudo gradient of transformation of the fibre $F^{\mathrm{f}}$ are used to estimate the stress in each material point of pre-impregnated fabric. Each material point is moving as in a continuum, 
ensured by the non-sliding of fibers due to fabric weaving and resin behaviour. Therefore, a nodal approximation for the displacement can be used. The energy $\Pi(u)$ of pre-impregnated fabric is obtained by a summation of membrane strain energy of not polymerised resin and elastic tensile strain energy of warps and weft fibers:

$$
\delta \Pi(\vec{u})=\int_{A}\left\{\sigma^{\mathrm{m}}\right\}:\left\{\delta \varepsilon^{\mathrm{m}}\right\} \mathrm{d} A+\sum_{\text {weft }} A_{0}^{\mathrm{f}} \int_{L} \sigma_{1}^{\mathrm{f}} \cdot \delta \varepsilon_{1}^{\mathrm{f}} \mathrm{d} s+\sum_{\text {warp }} A_{0}^{\mathrm{f}} \int_{L} \sigma_{2}^{\mathrm{f}} \cdot \delta \varepsilon_{2}^{\mathrm{f}} \mathrm{d} s-\int_{\Gamma_{\sigma}} \bar{t} \cdot \delta \vec{u} d \Gamma
$$

where $h_{0}$ denotes the initial thickness of the fabric, $A_{0}^{\mathrm{f}}$ is the initial effective cross-section of the fibres and $\bar{t}$ is the external surface load applied along $\Gamma_{\sigma}$ of woven fabric. The effective cross section of the fibre $A_{0}^{\mathrm{f}}$ and the effective surface $A_{0}^{\mathrm{m}}$ of the membrane resin, that assumed no void between the fibre and the resin, were used are calculated by using the fibre volume fraction $V_{\mathrm{f}}$ of the woven fabric

$$
V_{\text {fabric }}=\sum_{\text {warp }} A_{0}^{\mathrm{f}} L^{\mathrm{f}}+\sum_{\text {weft }} A_{0}^{\mathrm{f}} L^{\mathrm{f}}+\left(1-V_{\mathrm{f}}\right) h_{0} A_{0}^{\mathrm{m}}=A_{0}^{\text {fabric }} h_{0}
$$

The energy due to the bending and locking has been omitted.

\section{Pre-impregnated fabric finite elements}

The first reason that modelling woven fabrics is difficult is the variety of deformation mechanisms available to the fibres and resin. The in-plane deformation of pre-impreganted woven fabrics may be grouped into different major modes: fibre stretching, fibre uncrimping, trellising, resin shearing and fibre sliping. These five meso-level modes of deformation combine to create the non-linear anisotropic response of woven fabrics. A comprehensive model for preimpregnated woven fabrics must track the evolving geometry of the meso-structure as well as account for all of the major meso-level modes of deformation. A faithful representation of the geometry (fibre + resin) and modes of deformation is essential for the accurate prediction of the macroscopic response of the pre-preg fabric (Figure 2).

The spatial equilibrium of composite material on the actual configuration is established in terms of non-linear equations: kinematic non-linearity, material non-linearity and contact with friction non-linearity. It is linearised for each load increment by an iterative Newton method. It should be emphasised that during the motion, nodes and elements are permanently attached

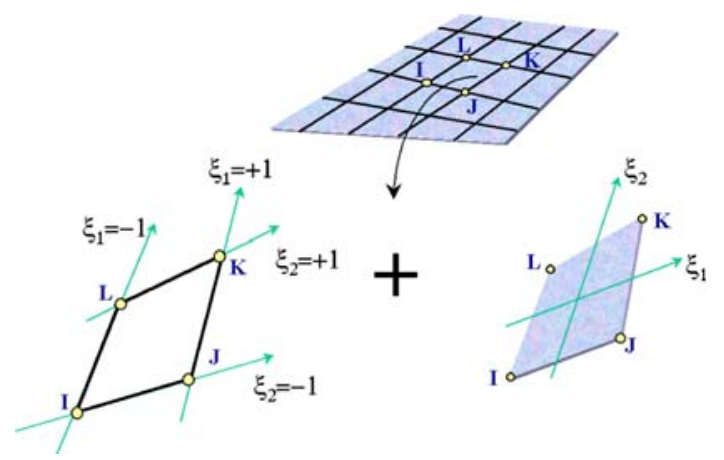

Figure 2. Bi-component finite element: FRQ4 connected to truss elements. 
to the material points with which they were initially associated. Consequently, the subsequent motion of unit cell is fully described in terms of the current nodal positions as:

$$
x=\sum_{k=1}^{4} N_{k}(\xi, \eta) X_{k}+\sum_{k=1}^{4} N^{k}(\xi, \eta) u_{k}
$$

The continuum response at each material point on the pre-impreganted fabric is obtained through homogenisation of the unit cell response. Once the deformed geometry of the unit cell is known, the forces in the fibres and the resin are determined from the constitutive relations. In order to convert the fibre and the resin forces into a continuum-level stress measure, the stress on the boundary of the unit cell is computed. The unit cell is composed of bi-component membrane and truss elements representative of resin and fibres, respectively.

For the fibres behaviour, truss finite elements of Abaqus library are used to characterise the warp and weft deformation. For the membrane resin behaviour, we have developed new finite element FRQ with degrees of freedom representing the macroscopic displacement of the fabric. We have implemented this element into the standard finite element code Abaqus/ Implicit with the user element subroutine. The concept of fibre plane rotation FRQ, proposed by Ayad (1993), is described through the four nodes element. At each node $k$ is assigned an additional rotation noted as $\theta_{z k}$. This concept is different from those of 'Vertex Rotations' (Allman, 1984) and 'Drilling Rotations' (Bergan \& Felippa, 1985). The FRQ formulation of the element in the plan is detailed by Ayad, Rigolot, and Talbi (2001), it has been validated on standard test cases of elasticity plane. Applied to the membrane element type moving FRQ, the approximation of the displacement field is expressed by:

$$
\left\{\begin{array}{l}
u(x, y) \\
v(x, y)
\end{array}\right\}=\sum_{k=1}^{4} N^{k}\left\{\begin{array}{l}
u_{k} \\
v_{k}
\end{array}\right\}+\sum_{k=1}^{4} N^{k} \theta_{z k} \vec{n} \wedge \vec{r} \quad \text { with } \vec{r}=\left\{\begin{array}{l}
x-x_{k} \\
y-y_{k}
\end{array}\right\}
$$

where $\left(u_{k}, v_{k}\right)$ are the displacement degree of freedom of each node and $\left(\theta_{z}\right)$ is the rotation of the fiber $\vec{r}$ (connecting the material point $[x$ and $y]$ to node $k$ ) around the normal $\vec{n}$ at node $k$. The term $\theta_{z k} \vec{n} \wedge \vec{r}$ is introduced to enhance the behaviour of the membrane element.

For the quadrilateral element, the shape functions are given in the form:

$$
N^{k}=\left(1+\xi \xi_{k}\right)\left(1+\eta \eta_{k}\right) / 4
$$

Based on the approximation of small displacements, the strain-displacement relation can be written in $2 \mathrm{D}$ form as follows:

$$
\left\{\begin{array}{c}
\varepsilon_{11}^{\mathrm{m}} \\
\varepsilon_{22}^{\mathrm{m}} \\
\gamma_{12}^{\mathrm{m}}
\end{array}\right\}=[B]\left\{u_{\mathrm{n}}\right\}=\left\{\begin{array}{c}
u_{, x} \\
v_{, y} \\
u_{, y}+v_{, x}
\end{array}\right\}
$$

Using the above displacement interpolation, the strain tensor is given by 


$$
\begin{aligned}
\left\{\begin{array}{l}
\varepsilon_{11}^{\mathrm{m}} \\
\varepsilon_{22}^{\mathrm{m}} \\
\gamma_{12}^{\mathrm{m}}
\end{array}\right\}= & \left\{\begin{array}{ccc}
\sum_{k} N_{, x}^{k} & 0 & -\sum_{k} N_{, x}^{k}\left(y-y_{k}\right) \\
& \sum_{k} N_{, y}^{k} & \sum_{k} N_{, x}^{k}\left(x-x_{k}\right) \\
\sum_{k} N_{, y}^{k} & \sum_{k} N_{, x}^{k} & \left(-\sum_{k} N_{, y}^{k}\left(y-y_{k}\right)+\sum_{k} N_{, x}^{k}\left(x-x_{k}\right)+2 \sum_{k} N^{k}\right)
\end{array}\right\} \\
& \times\left\{\begin{array}{l}
u_{k} \\
v_{k} \\
\theta_{k}
\end{array}\right\}
\end{aligned}
$$

where the derivation function is obtained by the equation

$$
\left\{\begin{array}{l}
N_{, x} \\
N_{, y}
\end{array}\right\}=\left[\begin{array}{ll}
j_{11} & j_{12} \\
j_{21} & j_{22}
\end{array}\right]\left\{\begin{array}{l}
N_{, \xi} \\
N_{, \eta}
\end{array}\right\}=\left[\begin{array}{ll}
x_{, \xi} & x_{, \eta} \\
y_{, \xi} & y_{, \eta}
\end{array}\right]\left\{\begin{array}{l}
N_{, \xi} \\
N_{, \eta}
\end{array}\right\}
$$

where $\left(j_{11}, j_{12}, j_{21}, j_{22}\right)$ are the components of the inverse Jacobian matrix.

For a linearly elastic, isotropic and homogeneous plate, the behaviour of the resin is given by

$$
\left\{\sigma^{\mathrm{m}}\right\}=\left\{\begin{array}{l}
\sigma_{11}^{\mathrm{m}} \\
\sigma_{22}^{\mathrm{m}} \\
\tau_{12}^{\mathrm{m}}
\end{array}\right\}=\frac{h_{0} E_{\mathrm{m}}}{1-v_{\mathrm{m}}^{2}}\left[\begin{array}{ccc}
1 & v_{\mathrm{m}} & 0 \\
v_{\mathrm{m}} & 1 & 0 \\
0 & 0 & 1-v_{\mathrm{m}}
\end{array}\right]\left\{\begin{array}{l}
\varepsilon_{11}^{\mathrm{m}} \\
\varepsilon_{22}^{\mathrm{m}} \\
\gamma_{12}^{\mathrm{m}}
\end{array}\right\}=\left[H^{\mathrm{m}}\right]\left\{\varepsilon^{\mathrm{m}}\right\}
$$

The fabric stiffness matrix of pre-impregnated fabric is the discrete sum of FRQ4 stiffness matrix and classical stiffness matrix of four truss element. One Hammer integration point is sufficient to compute exactly the truss stiffness and four Hammer points for FR quadrilateral finite elements.

\section{Remeshing procedure for pre-impregnated fabric}

The efficiency of adaptive refinement analysis depends on the shape of the elements, and so estimating the quality of element shape is requisite during the adaptive analysis being performed. Unfortunately, most posterior error estimates cannot evaluate the shape error of an element, so that some difficulties remain in the application of an adaptive analysis (Babuska et al., 1986; Baker, 1989; Gifford, 1979; Oden, Demkowicz, Rachowicz, \& Westermann, 1989; Zhu, Zacharia, \& Cescotto, 1997; Zienkiewicz \& Zhu, 1987). The use of finite element methods for problems where the domain evolves during the simulation presents a number of challenges that are not present in solutions for a fixed domain. Two high-level issues that must be considered when automating process simulations are: (i) when to remesh and (ii) how to remesh.

The criteria used to trigger a remesh are collectively called the remeshing criteria. Four sources of errors that influence the decision to remesh are:

- Geometric approximation errors (due the discretisation of the workpiece and the tools).

- Element distortion errors (error due to element shape).

- Mesh discretisation errors (errors in the solution due to use of specific basis functions on individual finite elements).

- Mesh rezoning errors (an issue critical to the successful use of remeshing in history dependent solution procedures is the transfer of the appropriate solution variables between meshes). 
The impact of the different types of errors encountered based on metrics to measure them will key a remeshing step. The process of remeshing focuses on controlling these errors so that the simulation can continue. The objective of the geometry update procedure is to take a finite element mesh representing the current state of the workpiece, and evolve the geometric representation of the workpiece to represent its real current deformed shape. This geometric representation is then discretised to generate a mesh consisting of valid, high-quality elements focused on controlling the mesh discretisation and distortion errors. The simulation of the composite fabric forming is based on an iterative process. At first, a coarse initial mesh of the part is generated with bi-component finite elements (FRQ4 quadrilateral element representing the resin behaviour connected to four truss elements representing the fibre behaviour) see Figure 3. At each step, a finite element computation is realised in order to simulate numerically the composite forming process for a small tools displacement. Then, the remeshing is applied after each increment if necessary, according to the following scheme:

(A) Definition of a physical size $\left(h_{\mathrm{P}}\right)$ map based on the adaptation of the mesh element size with respect to one of the mechanical fields. This physical size is defined with respect of one of the mechanical field. The shear angle can, for example, be chosen as mechanical field in order to define the physical size map. A physical size is calculated for each element of the mesh with the following non-linear analytical function:

$$
\left\{\begin{array}{l}
h_{\mathrm{P}}=\left(h_{\min }-h_{\max }\right)\left(\frac{\gamma}{\gamma_{\text {cri }}}\right)^{\beta}+h_{\max } \quad \gamma<\gamma_{\text {cri }} \\
h_{\mathrm{P}}=h_{\min } \quad \gamma \geq \gamma_{\text {cri }}
\end{array}\right.
$$

where $h_{\min }$ and $h_{\max }$ are the minimal and maximal element sizes, $\gamma_{\text {cri }}$ is a critical shear value from which the minimal size must be reached and $\beta$ is a parameter controlling the non-linear size variation. For a given element, the physical criterion represents the ratio between the average size of its edges $(\bar{h})$ and its physical size $\left(h_{\mathrm{P}}\right)$. If this ratio $\left.\overline{(h} / h_{\mathrm{P}}\right)$ is greater than a given threshold, the element must be refined.

(B) Definition of a geometrical size $\left(h_{\mathrm{G}}\right)$ map based on the geometric curvature of the part boundary. It represents the maximal angular gap between the normal to the element and the normals at its vertices. The normal vector $\vec{v}$ at node $\mathrm{P}$ can be defined as the weighted average of the unit normal vectors $\vec{N}_{i}(i=1, \ldots, m)$ to elements sharing node $\mathrm{P}$ :

$$
\vec{v}=\sum_{i=1}^{4} \alpha_{i} \vec{N}_{i} /\left\|\sum_{i=1}^{4} \alpha_{i} \vec{N}_{i}\right\|
$$

where $\alpha_{i}$ is the angle at $\mathrm{P}$ of the $i$ th element sharing P. The geometrical criterion applied to an element can be written as:
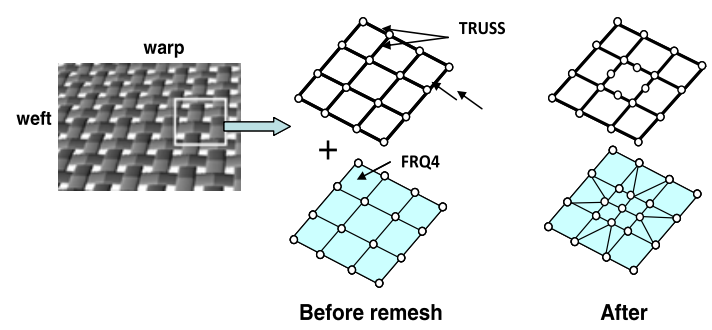

Figure 3. Remeshing procedure of pre-impregnated fabric. 


$$
\operatorname{Max}\left(\theta\left\langle\overrightarrow{v_{i}}, \vec{N}\right\rangle\right) \geq \theta_{\text {cri }}
$$

where $\vec{v}_{i}$ is the normal at vertex $i$ of the element, $\vec{N}$ is its normal and $\theta_{\text {cri }}$ is an angular gap threshold. The geometrical criterion allows to refine the mesh in the curved area (elements whose angular gap is greater than a given threshold) and to coarsen the mesh in the flat area. The smaller the angular gap threshold chosen by the user, the more the mesh of the part will be refined.

(C) Adaptive remeshing of the domain based on refinement and coarsening techniques with respect to the physical and geometrical sizes map $h=\operatorname{Min}\left(h_{\mathrm{P}}, h_{\mathrm{G}}\right)$. The adaptive remeshing technique consists of improving the mesh by coarsening and refinement methods in order to conform to the geometry of membrane and truss elements and the mechanical fields of the current part surface during deformation. Two consecutive steps are executed:

(1) Coarsening step during which the mesh is coarsened with respect to the physical size map.

(2) Refinement step during which the mesh is refined according to the geometrical size map and then to the physical size map.

(3) Define the deformed truss finite elements representing the fixed warp and weft fibres discretisation.

(4) Define the deformed FRQ4 finite elements representing the resin discretisation.

(5) Transfer the mechanical field of FRQ4 and Truss element from the old mesh to the new mesh.

\section{Application}

In this section, the proposed finite element formulation and the adaptive remeshing strategy is applied to solve woven fabric deformation problems. The user's linear quadrilateral element FRQ4 coupled to linear truss finite element of Abaqus library are used to simulate the preimpregnated shear test. The membrane finite element M3D4R or M3D3 coupled to truss element $\mathrm{T} 3 \mathrm{D} 2$ representing the fabric behaviour and the remeshing procedure are used to study the numerical simulations of busting and deep-drawing forming tests.

\subsection{Shear test}

Shearing of fabrics is a major deformation mode during stamping or draping. The picture frame test is probably the most popular method for the investigation of fabric shear behaviour. In this test, the load is applied at $45^{\circ}$ with respect to the fibre directions in order to get a trellis shear deformation in the sample. The shear test for fabrics involves the shearing of a fabric specimen, usually $200 \mathrm{~mm} \times 200 \mathrm{~mm}$ held within a picture hinged frame. Two diagonally opposite corners of the picture frame are pulled apart at a constant rate in a tensile testing machine. If it is assumed that the fabric is inextensible in the two fibre directions, there is only in-plane shear before wrinkling starts. On each fabric specimen, an orthogonal grid of $20 \mathrm{~mm} \times 20 \mathrm{~mm}$ was marked with a marker pen. The picture frame was mounted onto a Instron 4464 Instruments tensile testing machine and held in orthogonal shape (see Figure 4). The fabric was held on the frame in such a way as to allow rotation of the fibre bundles around the pins. The testing machine was then set in tensile mode at a constant crosshead speed. Various crosshead speeds were tried in the range of $10 \mathrm{~mm} / \mathrm{min}$. In the test, the displacement $(\Delta)$ and the load P are measured at the crosshead of the picture frame. The pre-impregnated fabric patches were modelled 

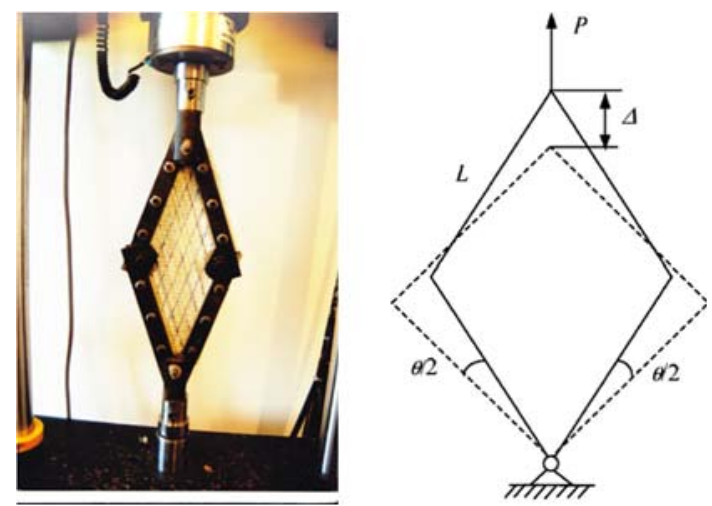

Figure 4. Geometry of the picture frame experiment.

by four-node FRQ4 elements connected with linear truss elements. Three mesh sizes are used in this study. They are coarse mesh M1 (25 elements), fine mesh M2 (100 elements) and very fine mesh M3 (2500 elements). The edge frame was modelled by rigid elements. Each edge of the frame can only rotate along the joints that connect to another frame edge. The imposed displacement applied at joint point with $(\Delta=75 \mathrm{~mm})$. Figure 4 shows the geometry of the picture frame experiments. The shear angle $\gamma$ is related to the displacement $(\Delta)$ as follows:

$$
\cos (\theta / 2)=\frac{\Delta}{2 L}+\cos (\pi / 4) \quad \gamma=\pi / 2-\theta
$$

The load data were translated into mean shear stress values along the fibre direction and Figure 5 displays force vs. shear angle curves. The predicted shear using FRQ4 user's element or DKT element of Abaqus library (Abaqus, 2009) is compared to the experimental values. Table 1 presents the data of the shear-locking angle from the experiment picture frame shear test compared to the predicted using different mesh sizes and theoretical shear values. Good agreement of shear-locking angle was found between the predicted and experiment values. The comparison of the shear angle map between the user FRQ element and the DKT

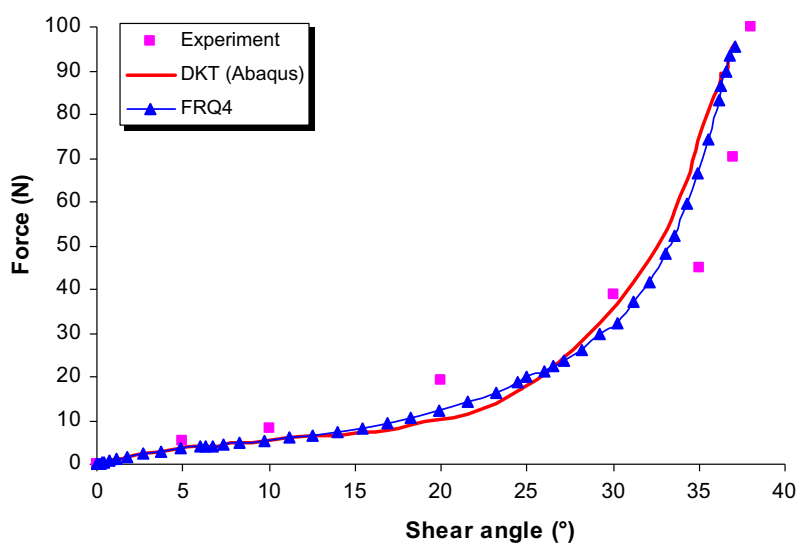

Figure 5. Force-shear angle of fibres comparison between DKT and FRQ4 and experiments. 
Table 1. Shear-locking angle for different element sizes.

\begin{tabular}{lccc}
\hline Elements & M1 (25 elements) & M2 (100 elements) & M3 (2500 elements) \\
\hline DKT Q4 (ABAQUS) & $35.12^{\circ}$ & $36.52^{\circ}$ & $37.41^{\circ}$ \\
FRQ4 & $35.07^{\circ}$ & $36.68^{\circ}$ & $37.56^{\circ}$ \\
Theoretical & & $36.91^{\circ}$ & \\
Experiment & & $38^{\circ}$ & \\
\hline
\end{tabular}

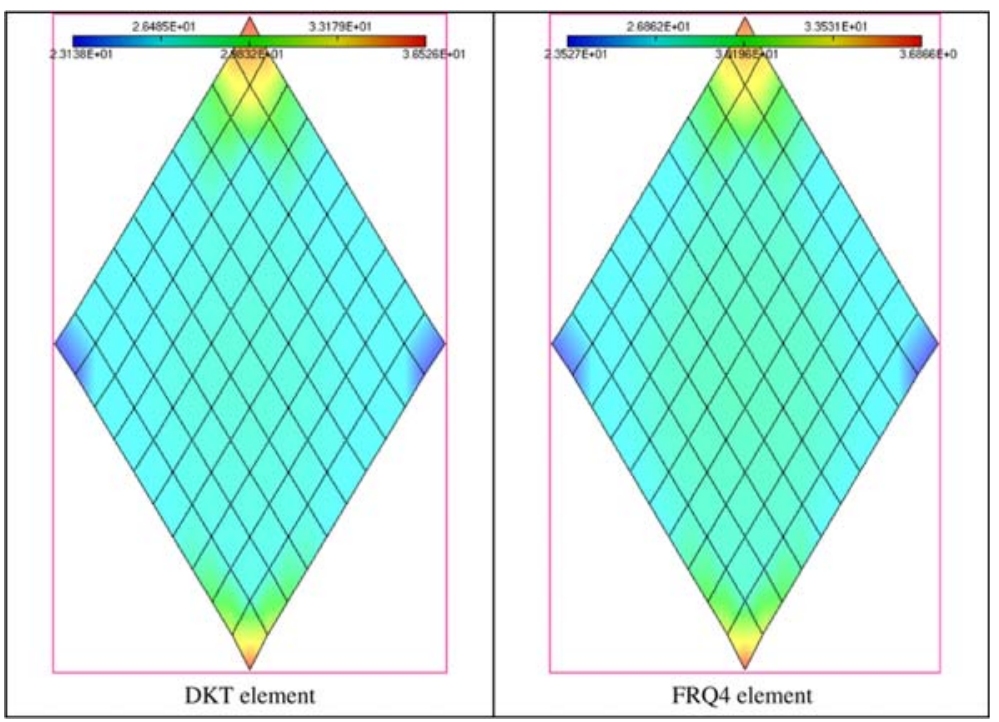

Figure 6. Iso-value of shear angle between warp and weft fibres comparison between the DKT and the FRQ4 finite elements.

Abaqus element is presented in Figure 6. We can notice that the two elements give very close shear angle distribution.

\subsection{Pressure burst tester}

The burst tester is used for measuring the bursting strength of sample materials subjected to an increasing hydrostatic pressure. This pressure is applied to a circular region of the specimen via an elastic diaphragm. The specimen is firmly held round the edge of this circular region by a pneumatic clamping device. When the pressure is applied, the specimen deforms together with the diaphragm. This method is used to determine the pressure required to burst a textile fabric. The geometry of the undeformed tool and the deformed fabric is illustrated in Figure 7. The used balanced textile fabric (jersey) is composed of $77 \%$ polyamide fibres and $26 \%$ membrane elastane. The mechanical properties of the used textile fabric are given in (Cherouat et al., 2010). The proposed remeshing procedure is used to simulate the bursting of the fabric for $52 \mathrm{~mm}$ of punch displacement. Adaptive mesh corresponding to punch displacement of $u=24,36,48$ and $52 \mathrm{~mm}$ is shown in Figure 8. We can see that, the initial membrane fabric is computed using an initial coarse mesh (400 membrane quadrilateral Q4 elements and 802 truss elements), the mesh is again refined uniformly where elements are 


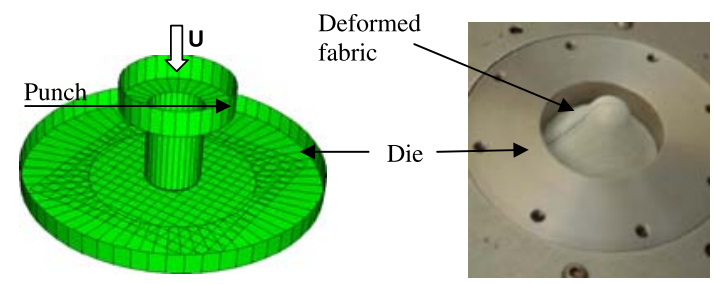

Figure 7. Geometry of bursting test and experimental result.
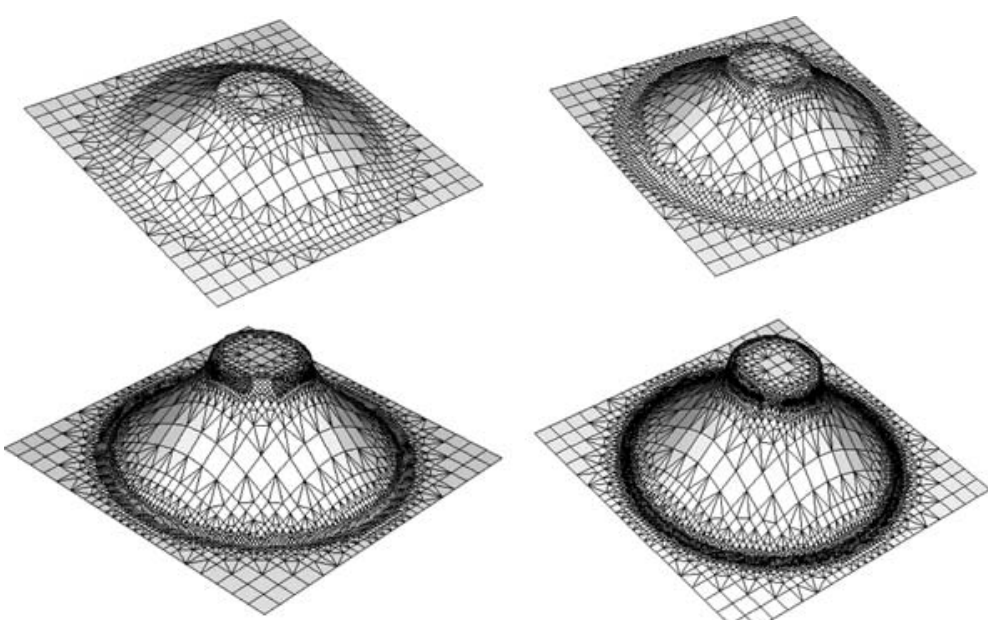

Figure 8. Deformed adaptive mesh at $u=24,36,48$ and $52 \mathrm{~mm}$.

curved in regions of large curvature. The final mesh of the elasthane has 12,468 T3 elements and 12,216 Q4 elements. The predicted bursting load vs. the punch displacement is compared with the experimental results shown in Figure 9. The maximum force $(80 \mathrm{kN})$ and the displacement $(65 \mathrm{~mm})$ corresponding to the initiation and the propagation of the damage inside the fabric. Good agreement between the predicted results and the experimental values was found.

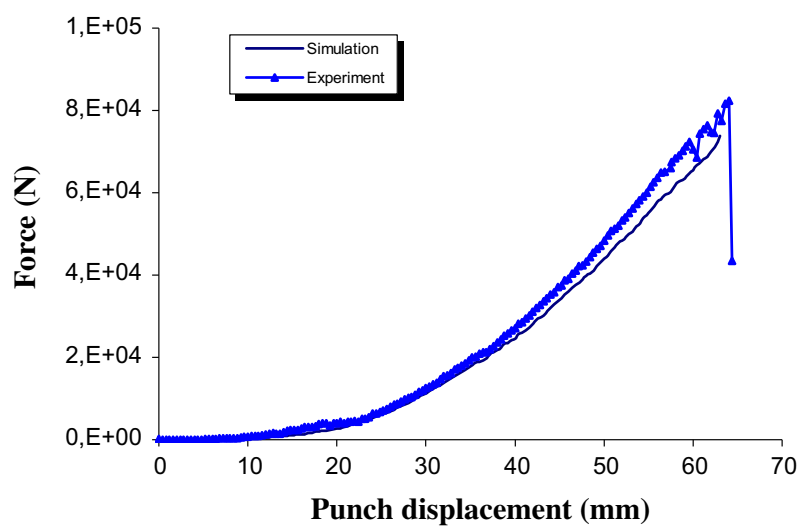

Figure 9. Force vs. punch displacement. 

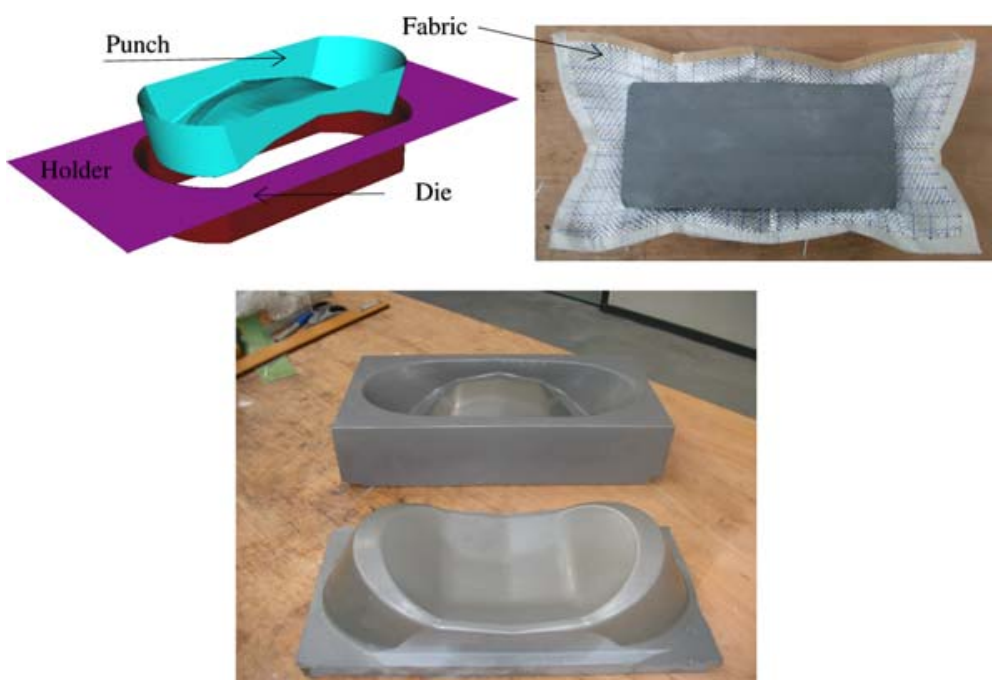

Figure 10. Composite fabric deep-drawing and tools.

\subsection{Deep-drawing of composite part}

The second example concerns the simulation of composite glass fabric stamping with complex tools using the mechanical approach and the computational remeshing procedure. The initial shape of the taffetas woven fabric is $\left(700 \times 350 \mathrm{~mm}^{2}\right)$. The high tensile stiffness along the warp, respectively, weft yarn direction is introduced via truss elements that connect the

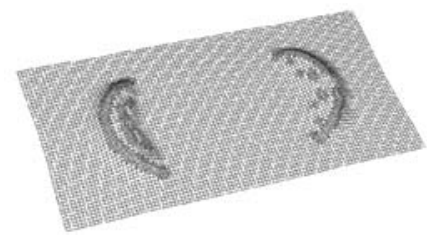

(a) Deformed mesh of resin $u=8 \mathrm{~mm}$

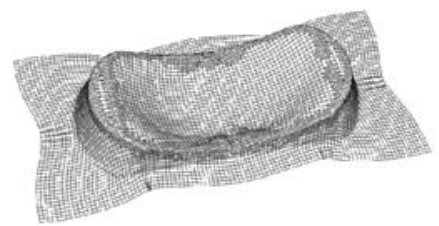

(c) Deformed mesh of resin $u=30 \mathrm{~mm}$

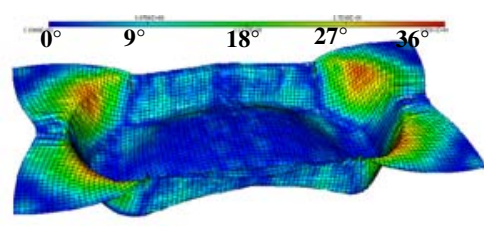

(e) Shear angle of fibres

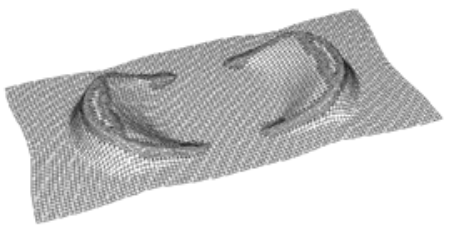

(b) Deformed mesh of resin $u=20 \mathrm{~mm}$

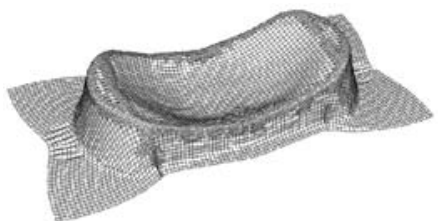

(d) Deformed mesh of resin $u=47 \mathrm{~mm}$

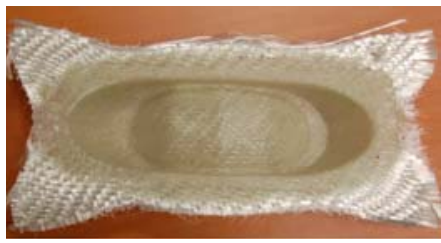

(f) Experiment for $u=47 \mathrm{~mm}$

Figure 11. Different deformed meshes and shear angles between fibres. 


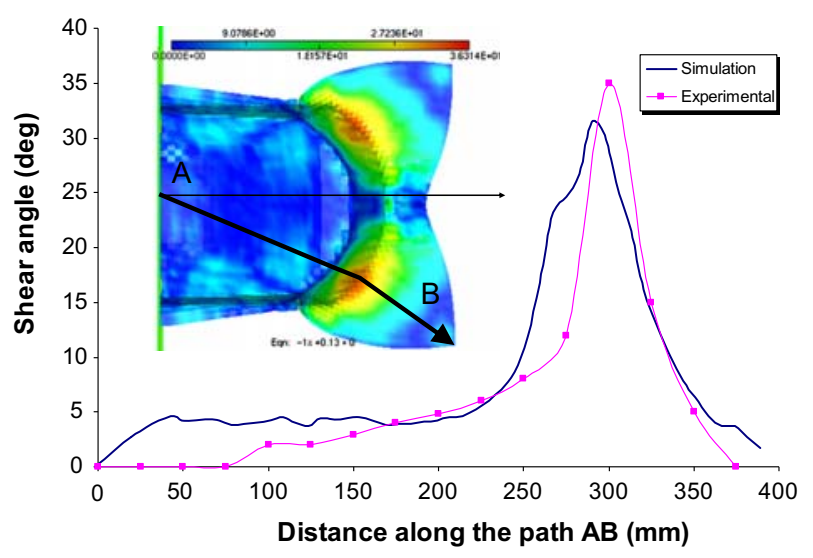

Figure 12. Shear angle along the diagonal path AB.

nodes of the 3D membrane element. The Young's modulus in warp and weft directions is $70 \mathrm{GPa}$, the Poisson coefficient is 0.22 and the density is $2619 \mathrm{~kg} / \mathrm{mm}^{3}$. The average fibre diameter is $20 \mu \mathrm{m}$ and the fabric areal weight is $800 \mathrm{k} / \mathrm{m}^{2}$.

The geometry of the stamping simulation is shown in Figure 10. The first order triangular T3 and quadrilateral Q4 membrane element type was used for the stamping. The blank holder force was $30 \mathrm{~N}$ and the punch stroke was $47 \mathrm{~mm}$. The friction coefficient between the glass fabric and the tools is 0.3 . The fibre direction is assumed $\left(0^{\circ} / 90^{\circ}\right)$. Numerical simulations obtained with adaptive remeshing are shown in Figure 11(a)-(d) for different punch displacements 8, 20, 30 and $47 \mathrm{~mm}$. The shear angle between fibres distribution was plotted in Figure 11(e). Figure 11(f) shows the adapted mesh of the warp and the weft to the curved shape of the punch. As shown in the Figure 12, maximum shear angle was observed at the highly curved area and such positions were almost same for all simulation cases. From the numerical simulation maximum shear angle was $35^{\circ}$.

\section{Conclusion}

The numerical analysis provides input data for the pre-processing of the computation of the final piece after polymerisation and gives the mechanical limits of the fabric during the forming process. Numerical examples concerning the deep-drawing of composite fabric demonstrated the efficiency of the proposed model. An adaptive remeshing technique for composite fabric forming process with refinement and coarsening procedures has been proposed. The implementation with continuum triangular and quadrilateral elements and truss element in the ABAQUS code allows us to validate the proposed approach for several types of problems.

\section{References}

Abaqus theory. (2009). User's Manual. Karlsson \& Sorensen, Inc. Hibbitt.

Allman, D.J. (1984). A compatible triangular element including vertex rotations for plane elasticity. Computers \& Structures, 19, 1-8.

Ayad, R. (1993). Eléments finis de plaque et coque en formulation mixte avec projection en cisaillement. Thèse de Doctorat, UTC, Mars.

Ayad, R., Rigolot, A., \& Talbi, N. (2001). An improved three-node hybrid-mixed element for Mindlin Reissner plates. International Journal for Numerical Methods in Engineering, 51, 919-942. 
Babuska, I., Zienkiewicz, O.C., Gago, J., \& Olivera D.A. (Eds.). (1986). Accuracy estimates and adaptive refinements in finite element computations. New York: Wiley.

Baker, T.J. (1989). Automatic mesh generation for complex three-dimensional regions using a constrained Delaunay triangulation. Engineering with Computers, 5, 161-175.

Bergan, P.G., \& Felippa, C.A. (1985). A triangular membrane element with rotational degrees of freedom. Computer Methods in Applied Mechanics and Engineering, 50, 25-69.

Bergsma, O.K., \& Huisman, J. (1988). Deep drawing of fabric reinforced thermoplastic. In C.A. Brebbia, W.P. de Wilde and W.R. Blain (Eds.), 2nd international conference of Computer Aided Design in Composite Material Technology, Southampton, (pp. 323-333). Berlin: Springer-Verlag.

Boisse, P., Buet, K., Gasser, A., \& Launay, J. (2001). Meso/macro-mechanical behaviour of textile reinforcements for thin composites. Composites Science and Technology, 61(3), 395-401.

Boisse, P., Gasser, A., Hagege, B., \& Billoet, J.L. (2005). Analysis of the mechanical behaviour of woven fibrous material using virtual tests at the unit cell level. International Journal of Materials Sciences, 40, 5955-5962.

Borouchaki, H., \& Cherouat, A. (2003). Drapage géométrique des composites. Comptes rendus de l'Académie des Sciences Paris, Serie II B, Mecanique des Solides et des Structures, 331, 437-442.

Borouchaki, H., Cherouat, A., \& Billoët, J.L. (1999). GeomDrap new computer aided design and manufacturing for advanced textile composites, Version 1. Troyes, France: UTT Internal Report.

Borouchaki, H., Cherouat, A., Laug, P., \& Saanouni, K. (2002). Adaptative meshing for ductile fracture prediction in metal forming. Comptes Rendus Mecanique, 330(10), 709-716.

Cherouat, A., \& Billoët, J.L. (2001). Mechanical and numerical modelling of composite manufacturing processes deep-drawing and laying-up of thin pre-impregnated woven fabrics. Journal of Materials Processing Technology, 118, 460-471.

Cherouat, A., \& Borouchaki, H. (2009). Present state of the art of composite fabric forming: geometrical and mechanical approaches. Materials, 2(4), 1835-1857.

Cherouat, A., Borouchaki, H., \& Giraud-Moreau, L. (2010). Mechanical and geometrical approaches applied to composite fabric forming. International Journal of Material Forming. doi: 10.1007/ s12289-010-0692-5

Cherouat, A., Gelin, J.C., Boisse, P., \& Sabhi, H. (1995). Numerical modeling of glass woven fabric deepdrawing using finite element method. European Journal of Computational Mechanics, 4, 159-182.

Cherouat, A., Borouchaki, H., \& Billoët, J.L. (2005). Geometrical and mechanical draping of composite fabric. European Journal of Computational Mechanics, 14(6-7), 693-708.

Cho, J.-W., \& Yang, D.-Y. (2002). A mesh refinement scheme for sheet metal forming analysis. In Proceedings of the 5th International Conference, NUMISHEET'02 (pp. 307-312).

Dafalias, Y.F. (1983). Corotational rates for kinematic hardening at large plastic deformations. Journal of Applied Mechanics, 50, 561-565.

Duhovic, M., \& Bhattacharyya, D. (2006). Simulating the deformation mechanisms of knitted fabric composites. Composites Part A: Applied Science and Manufacturing, 37(11), 1897-1915.

ElHami, A., Radi, B., \& Cherouat, A. (2009). Treatment of the composite fabric's shaping using a Lagrangian formulation. Mathematical and Computer Modelling, 49(7-8), 1337-1349.

Parsons, E.M., Weerasooriya, T., Sarva, S., \& Socrate, S. (2010). Impact of woven fabric: Experiments and mesostructure-based continuum-level simulations. Journal of the Mechanics and Physics of Solids, 58, 1995-2021.

Fan, J.P., Tang, C.Y., Tsui, C.P., Chan, L.C., \& Lee, T.C. (2006). 3D finite element simulation of deep drawing with damage development. International Journal of Machine Tools and Manufacture, 46 (9), 1035-1044.

Fourment, L., \& Chenot, J.L. (1994). Adaptive remeshing and error control for forming processes. Revue européenne des éléments finis, 3(2), 247-279.

Gifford, L.N. (1979). More on distorted isoparametric elements. International Journal for Numerical Methods in Engineering, 14, 290-291.

Gilormini, P., \& Roudier, P. (1993). Abaqus and Finite Strain, Rapport interne $n^{\circ} 140$. Cahchan, France.

Giraud-Moreau, L., Borouchaki, H., \& Cherouat, A. (2005). Remaillage adaptatif pour la mise en forme des tôles minces. Comptes rendus de l'Académie des Sciences Paris, Serie II B, Mécanique des Solides et des Structures, 333(4), 371-378.

Gommers, B., Verpoest, I., \& Van Houtte, P. (1996). Modelling the elastic properties of knitted fabricreinforced composites. Composites science and technology, 56, 685-694.

Hagège, B., Boisse, P., \& Billoët, J.-L. (2005). Finite element analyses of knitted composite reinforcement at large strain. European Journal of Computational Mechanics, 14(6-7), 767-776. 
Hancock, S.G., \& Potter, K.D. (2005). Inverse drape modelling - an investigation of the set of shapes that can be formed from continuous aligned woven fibre reinforcements. Composites Part A: Applied Science and Manufacturing, 36(7), 947-953.

Harrison, P., Clifford, M.J., Long, A.C., \& Rudd, C.D. (2004). A constituent-based predictive approach to modelling the rheology of viscous textile. Composites Part A: Applied Science and Manufacturing, 35, 915-931.

Hou, M., Ye, L., \& Mai, Y.W. (1997). Manufacturing process and mechanical properties of thermoplastic composite components. Journal of Materials Processing Technology, 63, 334-338.

Lim, T.C., Ramakrishna, S., \& Shang, H.M. (1999). Optimization of the formability of knitted fabric composite sheet by means of combined deep drawing and stretch forming. Journal of Materials Processing Technology, 89-90, 99-103.

Liu, L., Chen, J., Li, X., \& Sherwood, J. (2005). Two-dimensional macro-mechanics shear models of woven fabrics. Composites Part A: Applied Science and Manufacturing, 36, 105-114.

Lomov, S.V., Ivanov, D.S., Verpoest, I., Zako, M., Kurashiki, T., Nakai, H., \& Hirosawa, S. (2007). Meso-FE modelling of textile composites: Road map, data flow and algorithms. Composites Science and Technology, 67, 1870-1891.

Long, A.C. (2001). Process modelling for liquid moulding of braided performs. Composites Part A: Applied Science and Manufacturing, 32(7), 941-953.

Long, A.C., \& Rudd, C.D. (1994). A simulation of reinforcement deformation during the production of preform for liquid moulding processes. Proceedings of the Institution of Mechanical Engineers Part B: Management and Engineering Manufacture, 208, 269-278.

Luo, Y., \& Verpoest, I. (2002). Biaxial tension and ultimate deformation of knitted fabric reinforcements. Composites Part A: Applied Science and Manufacturing, 33, 197-203.

Mark, C., \& Taylor, H.M. (1956). The fitting of woven cloth to surfaces. Journal of the Textile Institute, $47,477-488$.

Oden, J.T., Demkowicz, L., Rachowicz, W., \& Westermann, T.A. (1989). Towards a universal h-p adaptive finite element strategy, part 2. A posteriori error estimation. Computer Methods in Applied Mechanics and Engineering, 77, 113-180.

Padmanabhan, K.A. (2008). Metal forming at very low strain rates. In Encyclopedia of Materials. Science and Technology (pp. 5384-5389). UK: Elsevier Science.

Peng, X., \& Cao, J. (2002). A dual homogenization and finite element approach for material characterization of textile composites. Composites Part B: Engineering, 33, 45-56.

Peng, X., \& Cao, J. (2005). A continuum mechanics-based nonorthogonal constitutive model for woven composite fabrics. Composites Part A: Applied Science and Manufacturing, 36, 859-874.

Pickett, A.K., Creech, G., \& de Luca, P. (2005). Simplified and advanced simulation methods for prediction of fabric draping. European Journal of Computational Mechanics, 14(6-7), 677-691.

Potluri, P., Sharma, S., \& Ramgulam, R. (2001). Comprehensive drape modelling for moulding 3D textile preforms. Composites Part A: Applied Science and Manufacturing, 32(10), 1415-1424.

Potluri, P., Parlak, I., Ramgulam, R., \& Sagar, T.V. (2006). Analysis of tow deformations in textile preforms subjected to forming forces. Composites Science and Technology, 66(2), 297-305.

Rozant, O., Bourban, P.E., \& Manson, J.A.E. (2000). Drapability of dry textile fabrics for stampable thermoplastic performs. Composites Part A: Applied Science and Manufacturing, 31, 1167-1177.

Rudd, C.D., \& Long, A.C. 1997. Liguid molding technologies. Cambridge: Woodhead Publishing.

Sharma, S.B., \& Sutcliffe, M.P.F. (2004). A simplified finite element model for draping of woven material. Composites Part A: Applied Science and Manufacturing, 35, 637-643.

Spencer, A.J.M. (2000). Theory of fabric-reinforced viscous fluid. Composites Part A: Applied Science and Manufacturing, 31, 1311-1321.

Lim, T.-C., \& Ramakrishna, S. (2002). Modelling of composite sheet forming: A review. Composites Part A: Applied science and manufacturing, 33, 515-537.

Ten Thije, R.H.W., Akkerman, R., \& Huetink, J. (2007). Large deformation simulation of anisotropic material using an updated Langrangian finite element method. Computer Methods in Applied Mechanics and Engineering, 196(33-34), 3141-3150.

Trochu, F., Ruiz, E., Achim, V., \& Soukane, S. (2006). Advanced numerical simulation of liquid composite molding for process analysis and optimization. Composites Part A: Applied Science and Manufacturing, 37, 890-902.

Umer, R., Bickerton, S., \& Fernyhough, A. (2008). Modelling the application of wood fibre reinforcements within liquid composite moulding processes. Composites Part A: Applied Science and Manufacturing, 39(4), 624-639. 
Van Der Ween, F. (1991). Algorithms for draping fabrics on doubly curved surfaces. International Journal for Numerical Methods in Engineering, 31, 1414-1426.

Vanclooster, K., Lomov, S.V., \& Verpoest, I. (2009). Experimental validation of forming simulations of fabric reinforced polymers using an unsymmetrical mould configuration. Composites Part A: Applied Science and Manufacturing, 40(4), 530-539.

Vilnis Frishfelds, F., Staffan Lundström, T., \& Jakovics, A. (2008). Bubble motion through non-crimp fabrics during composites manufacturing. Composites Part A: Applied Science and Manufacturing, $39(2), 243-251$.

Warby, M.K., Whiteman, J.R., Jiang, W.-G., Warwick, P., \& Wright, T. (2003). Finite element simulation of thermoforming processes for polymer sheets. Mathematics and Computers in Simulation, 61, 209-218.

Xue, P., Peng, X., \& Cao, J. (2003). A non-orthogonal constitutive model for characterizing woven composites. Composites Part A: Applied Science and Manufacturing, 34, 183-193.

Yu, W.R., Pourboghrat, F., Chung, K., Zamploni, M., \& Kang, T.J. (2002). Non-orthogonal constitutive equation for woven fabric reinforced thermoplastic composites. Composites Part A: Applied Science and Manufacturing, 33, 1095-1105.

Zhu, Y.Y., Zacharia, T., \& Cescotto, S. (1997). Application of fully automatic remeshing to complex metal forming analyses. Computers \& Structures, 62(3), 417-427.

Zienkiewicz, O.C., \& Zhu, J.Z. (1987). A simple error estimator and adaptive procedure for practical engineering analysis. International Journal for Numerical Methods in Engineering, 24, 337-357. 